\title{
Growth response of human colorectal tumour cell lines to treatment with afatinib (BIBW2992), an irreversible erbB family blocker, and its association with expression of HER family members
}

\author{
SAID ABDULLAH KHELWATTY ${ }^{1}$, SHARADAH ESSAPEN ${ }^{1,2}$, ALAN M. SEDDON ${ }^{1}$ and HELMOUT MODJTAHEDI ${ }^{1}$ \\ ${ }^{1}$ School of Life Sciences, Kingston University London, Kingston; ${ }^{2}$ St. Luke's Cancer Centre, \\ Royal Surrey County Hospital, Guildford, Surrey, UK
}

Received March 31, 2011; Accepted May 2, 2011

DOI: $10.3892 /$ ijo.2011.1054

\begin{abstract}
Despite the approval of the anti-epidermal growth factor receptor (EGFR) monoclonal antibodies (mAbs), cetuximab and panitumumab, for the treatment of colorectal cancer patients, there is currently no reliable predictive marker for response to therapy. In addition, the duration of response is often limited. Therefore, this study aimed to investigate the effect of afatinib, an irreversible erbB family blocker, as a single agent or in combination with cytotoxic drugs (5-fluorouracil, irinotecan and oxaliplatin) or mAb ICR62 on the proliferation of a panel of human colorectal tumour cell lines and the association between the expression levels of the EGFR family members and response to treatment. Of the cells examined, EGFR-overexpressing DiFi cells were the most sensitive to treatment with both afatinib $\left(\mathrm{IC}_{50}=45 \mathrm{nM}\right)$ and ICR62 $\left(\mathrm{IC}_{50}=4.33 \mathrm{nM}\right)$. Afatinib also inhibited the growth of other tumour cell lines with $\mathrm{IC}_{50}$ values which ranged from $0.33 \mu \mathrm{M}$ (CCL-221) to $1.62 \mu \mathrm{M}$ (HCT-116). A significant association was found between the co-expression of EGFR, human epidermal growth factor receptor (HER)-2 and HER-3 and response to treatment with afatinib $(\mathrm{R}=0.915, \mathrm{P}=0.021)$. Treatment with afatinib and cytotoxic drugs was accompanied by an increase in the proportion of these cells in the sub-G0/G1 and in the $\mathrm{S}$ and $\mathrm{G} 2 / \mathrm{M}$ phase of the cell cycle, respectively. We conclude that afatinib as monotherapy or in combination with other drugs shows activity in colorectal tumour cells and that determination of the co-expression of HER family members should be conducted in clinical trials using drugs targeting erbB signaling. This approach could lead to the identification
\end{abstract}

Correspondence to: Dr Helmout Modjtahedi, School of Life Sciences, Kingston University London, Kingston-upon-Thames, Surrey KT1 2EE, UK

E-mail: h.modjtahedi@kingston.ac.uk

Key words: epidermal growth factor receptor, human epidermal growth factor receptor-2, afatinib, colorectal cancer of a specific subpopulation of cancer patients more likely to benefit from erbB-directed therapy.

\section{Introduction}

Colorectal cancer (CRC) is the third most commonly diagnosed type of cancer $(1,230,000)$ and the fourth leading cause of cancer death $(608,000)$ worldwide (1). Despite major advances in our understanding of CRC biology and improvements in CRC screening, diagnosis and treatment, the majority of CRC patients are diagnosed with locally advanced or metastatic disease and have a poor outcome and die of their disease $(2,3)$. A major challenge is the identification of biological marker(s) which are important in predicting the progression of CRC. A further challenge is the development of novel and more specific therapeutic strategies for the treatment of this disease. The development of such markers could aid in the selection of a more specific subpopulation of CRC patients who would be more likely to benefit from such therapies and could also reduce unnecessary treatments and high healthcare costs (2).

In the past thirty years, the aberrant expression of members of the type-I growth factor receptor subfamily has been reported in a wide range of human epithelial malignancies and, in some studies, these were associated with a poor prognosis and resistance to conventional forms of therapies (4-7). The epidermal growth factor receptor (EGFR) is the prototype of the type-I growth factor receptor subfamily, which includes three additional known members: Human epidermal growth factor receptor (HER)-2 (Neu, c-erbB-2), HER-3 (c-erbB-3) and HER-4 (c-erbB-4). The binding of ligands to the external domain of EGFR leads to the formation of homo- or heterodimers with members of this family. Transphosphorylation of several tyrosine residues in the intracellular domain of these receptors leads to the activation of multiple downstream signaling pathways, including the ras/raf/MAPK, JAK-STAT and the PI-3/Akt pathways $(8,9)$. The biological consequences of aberrant erbB receptor family activation in human malignancies include: Increased cell proliferation, reduced apoptosis, increased angiogenesis, increased motility, invasion and metastasis which are the hallmarks of human cancers $(9,10)$. 
These observations have led to the strategic development and approval of several erbB receptor targeting drugs, including the anti-EGFR monoclonal antibodies (mAbs), cetuximab and panitumumab, the anti-HER-2 mAb, Herceptin, the small molecule EGFR tyrosine kinase inhibitors (TKIs), gefitinib and erlotinib, as well as lapatinib, which is a dual reversible EGFR and HER-2 TKI, for the treatment of cancer patients (11-15). Of the EGFR inhibitors, cetuximab and panitumumab have been approved for the treatment of patients with metastatic CRC. However, while these agents in combination with standard chemotherapy improve the survival of CRC cancer patients, the duration of response is often limited. In addition, no clear association has been reported between the expression of EGFR in CRC and response to the EGFR inhibitors (9). In some studies, the expression of other growth factor receptors (e.g., HER-2, HER-3 and IGF-IR), EGFR gene amplification, the presence of somatic EGFR mutations in exons 18 to 21, mutations of KRAS or PTEN, and the amplification of MET or the expression of autocrine growth factors (e.g., TGF $\alpha$, amphiregulin) have been suggested as indicators of response or resistance to therapy with the EGFR inhibitors $(9,10,16-19)$.

We have previously investigated the growth response of a panel of human colorectal tumour cell lines to treatment with our anti-EGFR mAb, ICR62, used alone and in combination with the reversible EGFR TKI, gefitinib (20). We found that, with the exception of the EGFR overexpressing cell line, DiFi, which was highly sensitive to treatment with both ICR62 and gefitinib, treatment with a combination of ICR62 and gefitinib did not enhance the growth inhibitory effect of the single agent in DiFi cells nor did it sensitize colorectal tumour cells that were insensitive to treatment with the single agent (20). The aim of this study was to evaluate the sensitivity of these colorectal tumour cell lines to treatment with afatinib (BIBW2992), an irreversible erbB family blocker (21-28) currently used in phase III clinical trials, and various cytotoxic drugs. Unlike gefitinib, afatinib is an anilinoquinazoline designed to covalently bind to erbB receptors and irreversibly inhibit their enzymatic activity. While afatinib has shown anti-proliferative activity in many cell lines and in vivo anti-tumour activity in preclinical lung cancer models containing various forms of EGFR mutations, including T790M point mutations (23), to our knowledge, this is the first study systematically investigating the response of human colorectal tumour cell lines to treatment with afatinib and/or cytotoxic drugs. The relationship between the expression of EGFR family members and growth inhibition by these agents and their effects on cell cycle distribution were also investigated.

\section{Materials and methods}

Tumour cell lines. The human colorectal tumour cell lines, CCL-221 (Dukes' C), CCL-225 (Dukes' C), CCL-228 (Dukes' B), CCL-244 (tumour stage unknown) and CCL-235 (Dukes' D), were purchased from the American Type Culture Collection (Manassas, VA, USA) and HCT-116 (tumour stage unknown) from the European Collection of Cell Culture (Porton Down, UK). Other human colorectal tumour cell lines used in this study included our two newly established cell lines, Colo-2 (Dukes' A) and Colo-13 (Dukes' C), and the EGFR overexpressing cell line, DiFi, which was established from a patient with familial adenomatous polyposis (FAP) and was kindly provided by Dr Z. Fan (MD-Anderson Cancer Centre) (20). All the cell lines were routinely cultured in Dulbecco's modified Eagle's medium (DMEM) (Sigma, UK) supplemented with $10 \%$ foetal bovine serum (FBS) (PAA Laboratories, UK) and the antibiotics, penicillin, streptomycin and neomycin, were maintained at $37^{\circ} \mathrm{C}$ in a humidified atmosphere with $5 \%$ $\mathrm{CO}_{2}$.

Antibodies, EGFR inhibitors and other reagents. The rat monoclonal antibody, ICR62 $\left(\operatorname{IgG}_{2 \mathrm{~b}}\right)$, was raised against the external domain of the EGFR on the breast carcinoma cell line (MDA-MB468) (29). The mouse monoclonal antibodies, HM50.67A and HM43.16B, were raised against the external domain of the HER-2 and EGFR, respectively (30). The mouse monoclonal antibodies, MAB3481 (anti-HER-3) and MAB11311 (anti-HER-4), were purchased from R\&D Systems (Oxford, UK). The secondary antibody used in this study was FITCconjugated rabbit anti-mouse IgG (Abd Serotech, UK). The irreversible EGFR/HER-2 TKI, afatinib, was kindly provided by Boehringer Ingleheim (Austria). The cytotoxic drugs, 5-fluorouracil (5-FU), irinotecan and oxaliplatin, were purchased from Sigma-Aldrich (Dorset, UK).

Flow cytometry. The cell surface expression of growth factor receptors was determined using FACS analysis. Approximately $1 \times 10^{6}$ tumour cells in $1 \mathrm{ml}$ of DMEM/2\% FBS were incubated with primary mouse antibodies or control medium or for $1 \mathrm{~h}$ by rotation at $4^{\circ} \mathrm{C}$. Tumour cells were washed three times by centrifugation for $5 \mathrm{~min}$ at $1,000 \mathrm{rpm}$ and resuspension in DMEM/2\% FBS, prior to incubation with FITC-conjugated goat anti-mouse IgG secondary antibody. Following rotation for $1 \mathrm{~h}$ at $4^{\circ} \mathrm{C}$, tumour cells were washed three more times and the final cell pellet was resuspended in FACSFlow buffer (Becton-Dickinson Ltd., UK). A minimum of 10,000 events were recorded by excitation with an argon laser at $488 \mathrm{~nm}$, and analysed using the FL-1 detector (FITC detector; $525 \mathrm{~nm}$ ) of a BD FACScalibur flow cytometer (Becton-Dickinson) using CellQuest Pro software.

Growth response studies. Tumour cells were seeded at a density of $5 \times 10^{3}$ cells/well in $100 \mu \mathrm{l}$ growth medium supplemented with $2 \%$ FBS in a 96-well plate. After 4-h incubation at $37^{\circ} \mathrm{C}$ (in a humidified atmosphere, in $5 \% \mathrm{CO}_{2}$ ) $100 \mu \mathrm{l}$ aliquots of doubling dilutions of the single agents or in combination were added to triplicate wells. Cells were incubated at $37^{\circ} \mathrm{C}$ until the cells in the wells containing only control medium were near confluent. Tumour cells were then fixed with $10 \%$ trichloroacetic acid (TCA) for $1 \mathrm{~h}$, washed with tap water, air dried and stained with $0.04 \%$ SRB in $1 \%$ acetic acid for a further $1 \mathrm{~h}$. Subsequently, the cells were washed with $1 \%$ acetic acid, air dried and SRB stain was solubilised with $10 \mathrm{mM}$ Tris-base (100 $\mu \mathrm{l}$ per well) and the absorbance of each well was measured at $565 \mathrm{~nm}$ using an Epoch plate reader (Thermo Fisher, UK). The initial number of cells (prior to treatment) was determined by setting up a control plate which was processed under the same conditions after 4-h incubation at $37^{\circ} \mathrm{C}$ without the inhibitors. The effect of afatinib in combination with other inhibitors was assessed using the combination index (CI) as described in the CalcuSyn software 


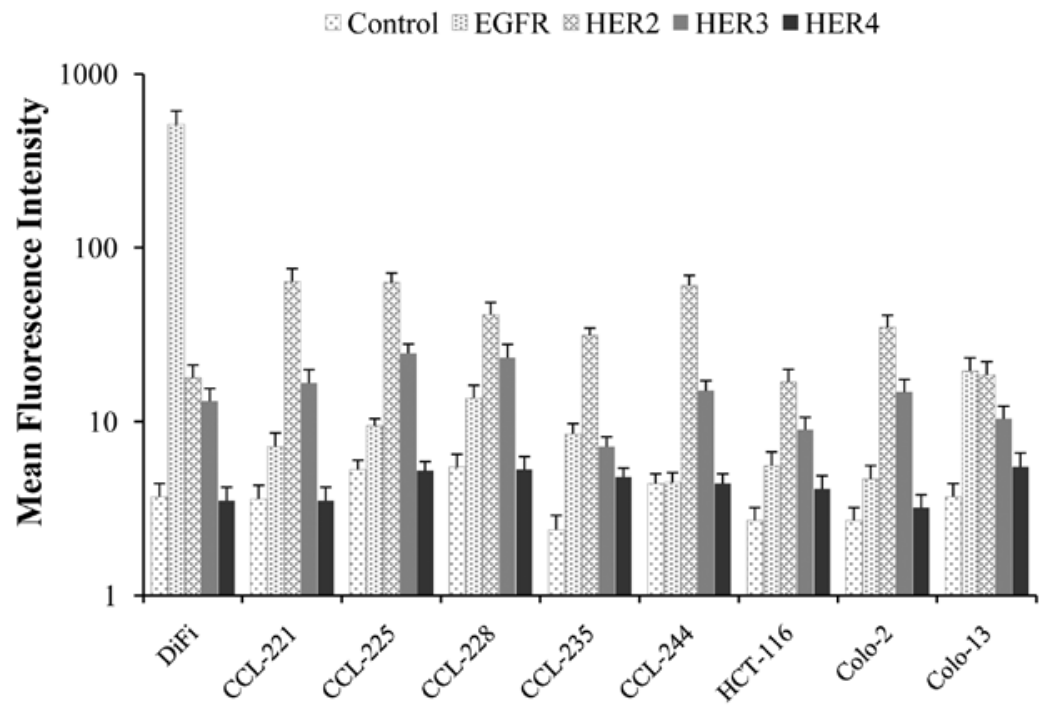

Cell Lines

Figure 1. The cell surface expression of EGFR family members measured by FACS analysis in colorectal tumour cell lines. Approximately $1 \times 10^{6}$ tumour cells were incubated for $1 \mathrm{~h}$ at $4^{\circ} \mathrm{C}$ with control medium or primary antibodies. Tumour cells were incubated with FITC-conjugated secondary antibody and 10,000 events were recorded and analysed for growth factor receptor expression as described in Materials and methods. Columns represent mean fluorescence intensity and bars the means $\pm \mathrm{SD}$.

manual. Data were analysed using Gen5 (Biotek, UK) and Calcusyn software (Biosoft, UK).

Statistical analysis. The relationship between the EGF family receptor expression and response to treatment was assessed using linear regression, and the one-way analysis of variance (ANOVA) test. A value of $\mathrm{P}<0.05$ was considered to be statistically significant.

Cell cycle distribution analysis. Approximately $2.5 \times 10^{5}$ tumour cells were seeded into $25 \mathrm{~cm}^{2}$ culture flasks containing $10 \mathrm{ml}$ of DMEM/2\% FBS plus afatinib, cytotoxic drugs or control medium. Following a 5-day incubation at $37^{\circ} \mathrm{C}(5 \%$ $\mathrm{CO}_{2}$ ), the supernatants were collected and the adherent cells were trypsinised and pooled together with the cell supernatant. The cells were then washed three times in cold PBS and the final resulting pellet was resuspended in $200 \mu \mathrm{l}$ of cold PBS and permeablised in $1 \mathrm{ml}$ of cold $70 \%$ ethanol (in PBS). Following an overnight incubation at $4{ }^{\circ} \mathrm{C}$, the tumour cells were then washed once in PBS and incubated with $0.5 \mathrm{ml}$ of propidium iodide (PI)/RNase buffer (Becton-Dickinson) for $30 \mathrm{~min}$ at room temperature in the dark. The PI-stained tumour cells were then excited at $488 \mathrm{~nm}$ and analysed using the FL-3 detector of a BD FACScalibur flow cytometer (Becton-Dickinson) and CellQuest Pro software.

\section{Results}

Expression of cell surface EGFR family members in human colorectal tumour cell lines. The cell surface expression of EGFR family members (EGFR/HER-1, HER-2/neu, HER-3 and HER-4) was detected by FACS analysis in reference to the control cell lines (Fig. 1). FACS analysis showed that the mean fluorescence intensities (MFIs) for EGFR expression ranged from 4.5 (CCL-244) to $513(\mathrm{DiFi})$ and for HER-2 expression ranged from 17 (HCT-116) to 64 (CCL-221). All colorectal tumour cell lines were found to be HER-4-negative while expressing low levels of HER-3 with MFI values ranging from 9 (HCT-116) to 25 (CCL-225) (Fig. 1).

Growth response of human colorectal tumour cell lines to treatment with afatinib and/or other inhibitors. Of the 9 colorectal tumour cell lines examined, DiFi was the most sensitive cell line to treatment with afatinib and complete inhibition was achieved at concentrations above $198 \mathrm{nM}$ $\left(\mathrm{IC}_{50}=45 \mathrm{nM}\right)$ (Fig. 2A, Table I). In contrast, mAb ICR62 and gefitinib induced complete growth inhibition of DiFi cells at concentrations above $6.25\left(\mathrm{IC}_{50}=4.33 \mathrm{nM}\right)$ and $400 \mathrm{nM}$ $\left(\mathrm{IC}_{50}=110 \mathrm{nM}\right)$, respectively (data not shown). The growth of CCL-244 and other colorectal tumour cell lines was also completely inhibited by afatinib but at concentrations above 1.5 and $3.1 \mu \mathrm{M}$, respectively with an $\mathrm{IC}_{50}$ which ranged from 318 (CCL-244) to $1.62 \mu \mathrm{M}$ (HCT-116) (Fig. 2A; Table I). Of the cytotoxic drugs tested, 5-FU was found to have the lowest $\mathrm{IC}_{50}$ values for the growth inhibition of CCL-221, CCL-225, CCL-244, Colo-13 and DiFi cells and oxaliplatin had the lowest $\mathrm{IC}_{50}$ values for the growth inhibition of CCL-235, Colo-2 and HCT-116 cells (Table I). 5-FU induced complete growth inhibition of DiFi cells at concentrations above $1.5 \mu \mathrm{M}$ $\left(\mathrm{IC}_{50}=200 \mathrm{nM}\right.$ ) (Fig. 2B; Table I). Similar to DiFi cells, Colo-13 was also found to be highly sensitive to treatment with 5 -FU $\left(\mathrm{IC}_{50}=390 \mathrm{nM}\right)$ compared to irinotecan $\left(\mathrm{IC}_{50}=1.93 \mu \mathrm{M}\right)$ and oxaliplatin $\left(\mathrm{IC}_{50}=1.05 \mu \mathrm{M}\right)$ (Table $\left.\mathrm{I}\right)$.

Previously, we examined the growth response of a panel of human colorectal tumour cell lines to treatment with our antiEGFR mAb, ICR62, and/or gefitinib, a reversible and selective EGFR TKI, and found that most colorectal tumour cell lines were relatively resistant to treatment with both inhibitors (20). Therefore, we investigated whether the treatment with the combination of afatinib and ICR62 or other standard therapy 
$\mathbf{A}$
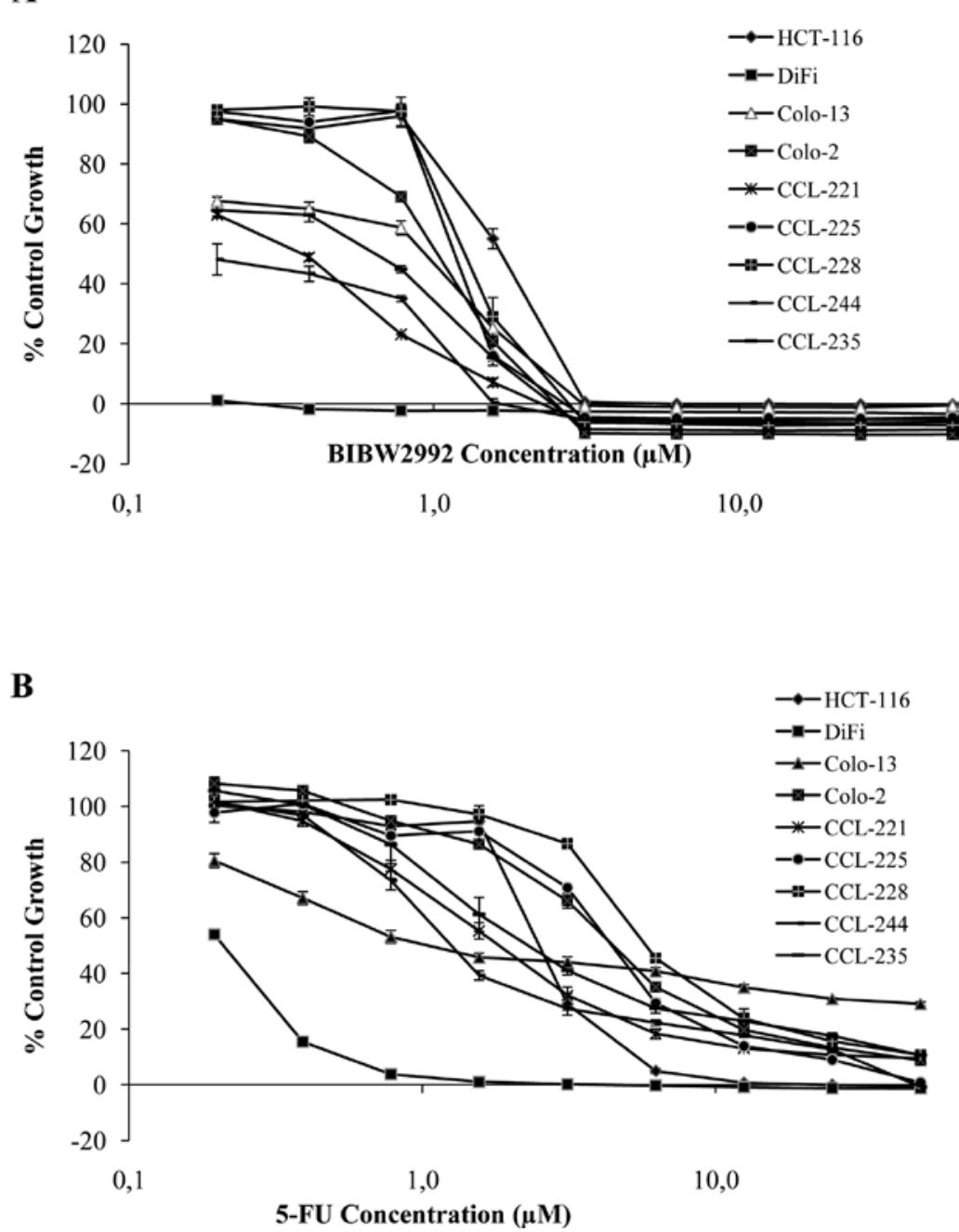

Figure 2. The effect of doubling dilutions of irreversible small molecule TKI BIBW2992 (A) and cytotoxic agent 5-FU (B) on the growth of human colorectal tumour cell lines. Tumour cell proliferation was calculated as a percentage of the control cell growth, as described in Materials and methods. Each point represents the mean of a triplicate value $\pm \mathrm{SD}$.

Table I. The $\mathrm{IC}_{50}$ values $(\mu \mathrm{M})$ for cytotoxic drugs and BIBW2992 against a panel of human colorectal tumour cells.

\begin{tabular}{lccccccccc}
\hline Inhibitors & CCL-221 & CCL-225 & CCL-228 & CCL-235 & CCL-244 & Colo-2 & Colo-13 & DiFi & HCT-116 \\
\hline 5-FU & 1.62 & 4.66 & 5.16 & 2.35 & 1.25 & 4.00 & 0.39 & 0.20 & 2.67 \\
Irinotecan & 3.47 & 6.13 & 2.22 & 7.38 & 10.93 & 4.91 & 1.93 & 0.76 & 4.41 \\
Oxaliplatin & 7.15 & 11.93 & 2.30 & 0.99 & 2.54 & 3.33 & 1.05 & 1.59 & 1.57 \\
BIBW2992 & 0.33 & 1.47 & 1.35 & 0.71 & 0.32 & 1.09 & 1.08 & 0.045 & 1.62 \\
ICR62 & $\mathrm{n} / \mathrm{a}$ & $\mathrm{n} / \mathrm{a}$ & $\mathrm{n} / \mathrm{a}$ & $\mathrm{n} / \mathrm{a}$ & $\mathrm{n} / \mathrm{a}$ & $\mathrm{n} / \mathrm{a}$ & $\mathrm{n} / \mathrm{a}$ & 0.004 & $\mathrm{n} / \mathrm{a}$ \\
\hline
\end{tabular}

n/a, Not available.

would enhance the growth inhibitory effect of the single agent in a sub-panel of colorectal tumour cell lines established from patients at different stages of the disease [i.e., Colo-2 (Dukes' A), CCL-228 (Dukes' B), CCL-221 (Dukes' C) and CCL-235 (Dukes' D)], as well as DiFi cells established from a patient with FAP. We found that the combination of afatinib with both ICR62 (CI=0.60; Table II) or 5-FU (CI=0.45; Table II) was synergistic and increased the growth inhibition of the EGFR overexpressing DiFi cells, thus differing from previous observations with the ICR62/gefitinib combination. The combination of afatinib with 5-FU had a nearly additive effect on the growth inhibition of CCL-235 cells $(\mathrm{CI}=0.95)$. The same combination was found to have antagonistic effects in CCL-228, CCL-221 and Colo-2 cells (Table II). 
A

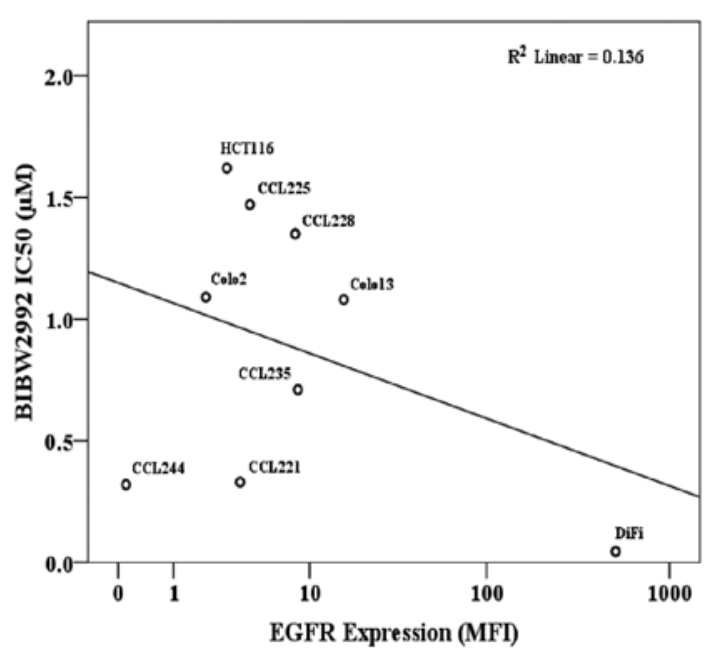

B

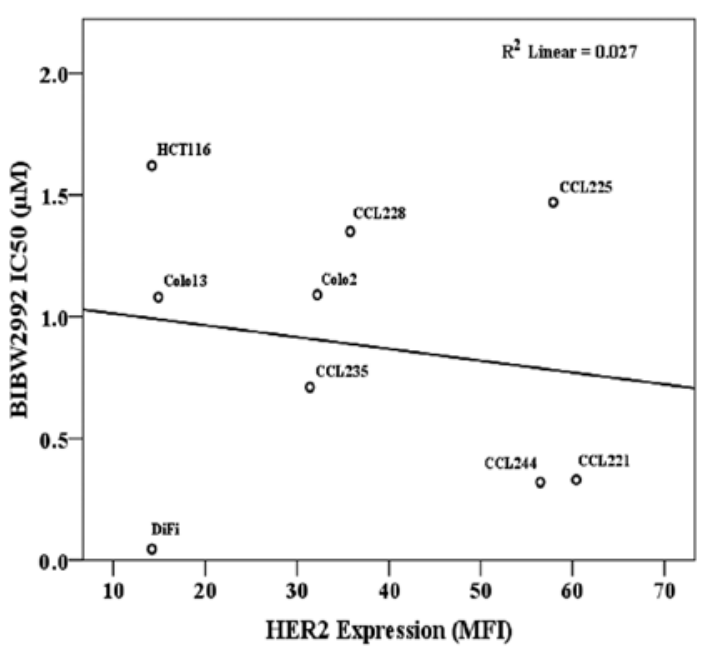

C

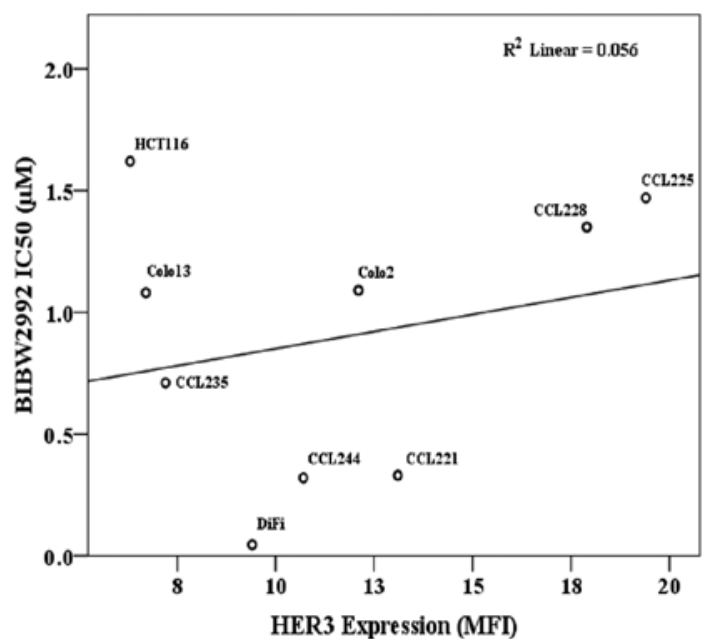

Figure 3. Linear regression analysis of EGFR (A), HER-2 (B) and HER-3 (C) expression versus response to BIBW2992 represented as $\operatorname{IC}_{50}(\mu \mathrm{M})$ in a panel of human colorectal tumour cell lines.

Relationship between the expression of EGFR family members and response to treatment. In order to determine whether there was a statistically significant relationship between the expression of EGFR, HER-2, HER-3 and HER-4 and sensitivity to treatment with afatinib, we conducted linear regression
Table II. CI of BIBW2992 in combination with 5-FU in the treatment of human colorectal tumour cell lines.

\begin{tabular}{llcl}
\hline Agents & Cell line & CI & \multicolumn{1}{c}{ Effect } \\
\hline BIBW2992+5FU & Colo-2 & 1.52 & Antagonism \\
BIBW2992+5FU & CCL-228 & 1.43 & Moderate antagonism \\
BIBW2992+5FU & CCL-221 & 1.77 & Antagonism \\
BIBW2992+5FU & CCL-235 & 0.95 & Nearly additive \\
BIBW2992+5FU & DiFi & 0.45 & Synergism \\
BIBW2992+ICR62 & DiFi & 0.60 & Synergism $^{\text {a }}$ \\
\hline
\end{tabular}

${ }^{\text {aBIBW} 2992 ~ i n ~ c o m b i n a t i o n ~ w i t h ~ I C R 62 . ~}$

analysis of the $\mathrm{IC}_{50}$ values of afatinib against the MFI values of each EGFR family member. No significant association was found between the expression of EGFR $(\mathrm{R}=0.558, \mathrm{P}=0.119)$, HER-2 $(\mathrm{R}=0.164, \mathrm{P}=0.673)$ or HER-3 $(\mathrm{R}=0.236, \mathrm{P}=0.541)$ and the response to afatinib (Fig. 3). However, there was a significant association between the co-expression of EGFR, HER-2 and HER-3 and the response to treatment with afatinib $(R=0.915$, $\mathrm{P}=0.021)$.

Changes in cell cycle phase distribution of human colorectal tumour cell lines treated with afatinib and cytotoxic drugs. Finally, we examined the changes in the cell cycle phase distribution of human colorectal tumour cell lines following treatment with afatinib and cytotoxic drugs using FACS analysis. Treatment of these cell lines with afatinib effectively increased the proportion of the cells in the sub-G0/G1 phase of the cell cycle in all cell lines (Fig. 4). This was accompanied by a reduction in the proportion of cells in the G1, S and $\mathrm{G} 2 / \mathrm{M}$ phases of the cell cycle. In contrast, treatment of these cell lines with cytotoxic drugs increased the proportion of the cells in the S and G2/M phase of the cell cycle (Fig. 4).

\section{Discussion}

The aberrant expression of EGFR has been reported in a wide range of human cancers and has been associated with metastasis and poor prognosis $(5,7,10,31)$. This has resulted in the development of molecular therapies targeting EGFR and the subsequent approval of anti-EGFR monoclonal antibodies, such as cetuximab and panitumumab, for the treatment of patients with various types of cancer including metastatic CRC $(11,14)$. However, despite extensive studies, there are currently no clear markers for predicting the response to therapy with the EGFR inhibitors (9). In particular, there has been no clear association between the expression of EGFR and response to anti-EGFR inhibitors $(9,32,33)$. Many studies have assessed the status of other markers downstream of the EGFR, such as mutations in KRAS, BRAF, PIK3CA and the loss of PTEN as a negative predictive marker of response to anti-EGFR therapies $(9,34)$. Of these, KRAS mutations occur in about $30-40 \%$ of CRC patients and are generally associated with resistance to therapy with anti-EGFR therapy (9,35-38). Consequently, the provisional clinical opinion of the American 
A

CCL-244

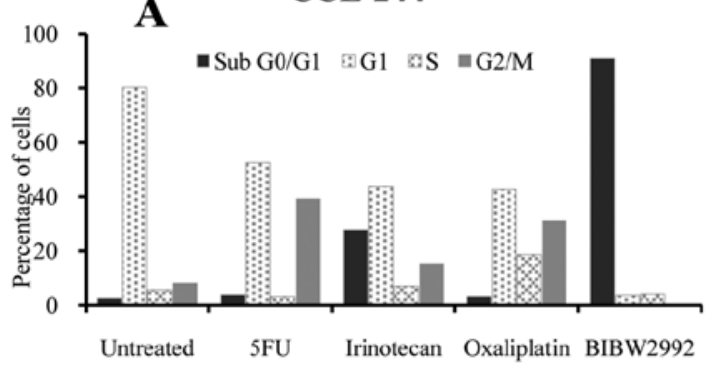

DiFi

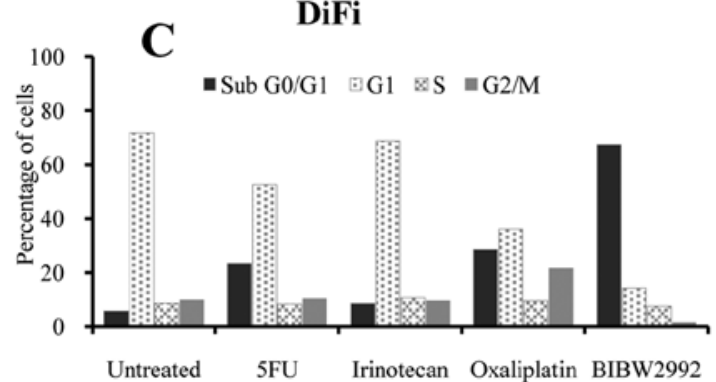

E

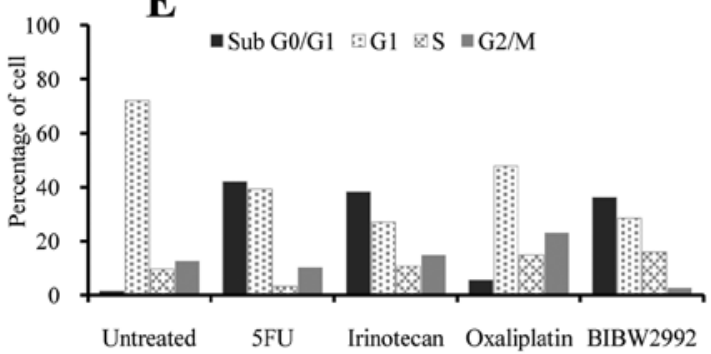

\section{G CCL-225}
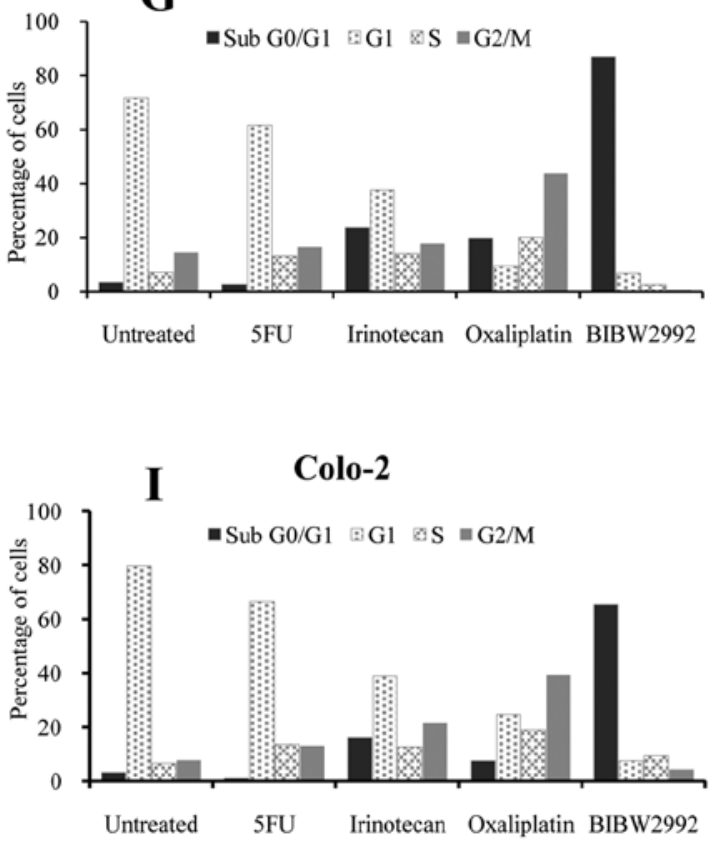
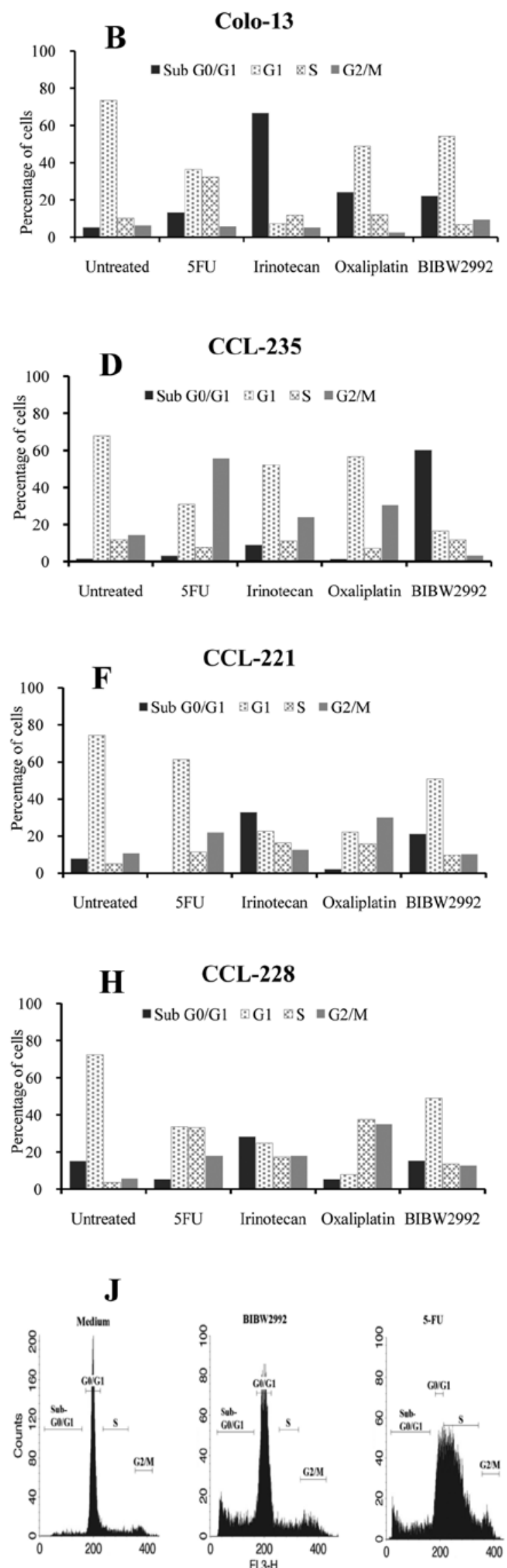

Figure 4. The effect of small molecule TKIs and the cytotoxic agent, 5-FU, on the cell cycle distribution of a large of panel of human colorectal tumour cell lines. Tumour cells were incubated for 5 days in DMEM/2\% FBS containing inhibitory concentrations of BIBW2992 and 5-FU or control medium. Following treatment, the cells were harvested and analysed for DNA content using FACS analysis as described in Materials and methods. The DNA histograms for the Dukes' C human colorectal tumour cell line, Colo-13, treated with control medium, BIBW2992 and 5-FU (J) and the percentage of the panel of human colorectal tumour cell lines in the sub-G0/G1, G1, S and G2/M phases of the cell cycle treated with BIBW2992 and cytotoxic drugs (A-I). 
Society of Clinical Oncology is that all patients with metastatic CRC who are candidates for therapy with anti-EGFR antibodies should have their tumour tested for KRAS mutations and if KRAS mutation in codon 12 or 13 is present, then such patients should not be given therapy with anti-EGFR antibodies as a part of their treatment (39). However, clinical responses with EGFR-targeting antibodies were not noted in all patients with the wild-type KRAS and there were rare cases in which patients with the KRAS mutations responded to treatment with anti-EGFR mAbs. For example, Amado et al analysed tumours from 124 panitumumab-treated metastatic CRC patients. They found a partial response in only 21 (i.e., $17 \%$ ) of 124 patients with wild-type KRAS (37). In the current preclinical investigation, we did not find any clear association between KRAS status of the human colorectal tumour cell lines and response to treatment with afatinib. The majority of colorectal tumour cell lines in this study contained KRAS mutations (i.e. CCL-221, CCL-225, CCL-228, CCL-235 and HCT-116) (40,41). We found that both CCL-244, expressing wild-type KRAS (42), and CCL-221 mutated KRAS were equally sensitive to treatment with afatinib with $\mathrm{IC}_{50}$ values of $0.32 \mu \mathrm{M}$ and $0.33 \mu \mathrm{M}$ (Table I). Both cell lines displayed poor sensitivity $(>1 \mu \mathrm{M})$ to the chemotherapeutic agents tested. These results suggest that the KRAS status alone is not a reliable indicator of response to treatment with small molecule erbB inhibitors and therefore, there is a need for identification of additional predictive biomarkers.

To this end, we examined the cell surface expression of all EGFR family members in a large panel of human colorectal tumour cell lines and determined whether there was any association between their expression levels and response to treatment with afatinib, mAb ICR62 and/or other standard therapies. Of the 9 colorectal tumour cell lines studied, only DiFi cells significantly overexpressed EGFR and these cells were highly sensitive to growth inhibition by both afatinib (Fig. 2A) and mAb ICR62 (Table I). The sensitivity of other EGFR overexpressing human tumour cell lines to growth inhibition by the EGFR inhibitors has also been reported in other studies $(20,29,43)$. However, to our knowledge there are only two studies which examine the expression pattern and prognostic significance of all EGFR family members in CRC patients $(44,45)$. In one study, Lee et al examined 125 Dukes' A-D patient tumour samples and found that 52, 34, 45 and $27 \%$ of the cases were EGFR- (64 of 125), HER-2- (44 of 125), HER-3- (46 of 125) or HER-4- (27 of 125) positive, respectively (44). In another study, Baiocchi et al examined the expression patterns of the EGFR family members in 109 patients with high-risk stage II and III CRC and reported EGFR, HER-2, HER-3 and HER-4 positivity in 58, 8, 70 and $11 \%$ of the cases, respectively (45). These results suggest that the co-expression of EGFR family members is common in patients with CRC. Of note, while we did not find any significant association between the expression of EGFR, HER-2 or HER-3 and response to afatinib, there was a significant association between the co-expression of EGFR, HER-2 and HER-3 and response to treatment with afatinib $(R=0.915$, $\mathrm{P}=0.021$ ). Taken together, these results suggest the need for erbB receptor co-expression analyses in future studies in order to assess their predictive value for response to therapy with small molecule erbB inhibitors.
Afatinib has previously been shown to be effective in inhibiting the growth in vitro and in vivo of EGFR and HER-2 expressing tumours $(23,46)$. In this study, afatinib inhibited the proliferation of all human colorectal tumour cell lines and the $\mathrm{IC}_{50}$ values for afatinib were found to be up to 50 times lower compared to gefitinib (20) (data not shown). At the maximum concentration of $200 \mathrm{nM}$ of ICR62, only DiFi cells were highly sensitive to growth inhibition and complete growth inhibition of DiFi cells was achieved at concentrations above $6.25 \mathrm{nM}\left(\mathrm{IC}_{50}=4.33 \mathrm{nM}\right)$. We have reported previously that while the mechanisms of action of mAb ICR62 differ from the reversible EGFR TKI gefitinib, dual targeting of the EGFR by a combination of ICR62 and gefitinib was not superior to treatment with either agent alone (20). Therefore, we examined the effect of co-targeting EGFR in colorectal tumour cells with a combination of ICR62 and afatinib and found that treatment with a combination of the two agents was superior to treatment with either single agent in DiFi cells. Similarly, superior effects of the afatinib/5-FU combination were noted when tested in DiFi cells (Table II). We found that the marked anti-proliferative effect of afatinib on our panel of human colorectal tumour cell lines was accompanied by substantial increases in apoptotic cells and cell cycle arrest in the G0/G1 phase (Fig. 4). Afatinib has previously been shown to cause cell cycle arrest in G0/G1 in other tumour cell lines (46). Treatment of the same cells with the cytotoxic drugs caused a blockade in the $\mathrm{S}$ and $\mathrm{G} 2 / \mathrm{M}$ phase of the cell cycle (Fig. 4). As expected, the mode of action of 5-FU differs from that of afatinib and superior growth inhibition of human colorectal tumour cells may be achieved when it is used in combination. However, while treatment with a combination of afatinib and 5-FU produced a synergistic effect in DiFi cells, which are sensitive $(<1 \mu \mathrm{M})$ to both single agents, such a combination produced antagonistic effects in three of the human colorectal tumour cell lines used in this study (Table II). The lower sensitivity $(>1 \mu \mathrm{M})$ of these cell lines to single agent treatments may reflect the need to confirm proper target modulation by the respective combination partners. These results clearly demand further investigation of the therapeutic potential of erbB inhibitors in combination with other therapeutic agents. They also reflect the need for properly preselecting patients entering clinical trials based on their erbB pathway deregulation as assessed by mutation, overexpression or co-expression patterns of erbB receptors and cognate ligands.

In conclusion, in this in vitro study we determined the expression and predictive value of EGFR family members for response to treatment with the irreversible erbB family blocker, afatinib, in a panel of CRC cell lines and found that the co-expression of EGFR, HER-2 and HER-3 is associated with response to treatment with afatinib. Our results underline the need for further investigation into the predictive value of EGFR family members for response to treatment with small molecule erbB inhibitors, such as afatinib, when used as a single agent or in combination with other standard chemotherapeutic agents in patients with CRC.

\section{Acknowledgements}

We are grateful to the BRIGHT charity (UK) for supporting this study, Boehringer Ingleheim (Austria) for the provision of 
the dual irreversible small molecule TKI afatinib, and Dr Z. Fan for providing DiFi cells.

\section{References}

1. Ferlay J, Shin HR, Bray F, Forman D, Mathers C and Parkin DM Estimates of worldwide burden of cancer in 2008: GLOBOCAN 2008. Int J Cancer 2893-2917, 2010.

2. Bujanda L, Sarasqueta C, Hijona E, et al: Colorectal cancer prognosis twenty years later. World J Gastroenterol 16: 862-867, 2010.

3. Seront E, Marot L, Coche E, Gala J-L, Sempoux C and Humblet Y: Successful long-term management of a patient with late-stage metastatic colorectal cancer treated with panitumumab. Cancer Treat Rev 36: S11-S14, 2010

4. Gullick WG: Prevalence of aberant expression of the epidermal growth factor receptor in human cancers. Br Med Bull 47: 87-98, 1991.

5. Modjtahedi H and Dean C: The receptor for EGF and its ligands: expression, prognostic value, and target for therapy in cancer. Int J Oncol 4: 277-296, 1994

6. Yarden Y: The EGFR family and its ligands in human cancer: signalling mechanisms and therapeutic opportunities. Eur J Cancer 37: 3-8, 2001.

7. Nicholson RI, Gee JW and Harper ME: EGFR and cancer prognosis. Eur J Cancer 37: 9-15, 2001.

8. Lo H-W, Hsu S-C and Hung M-C: EGFR signaling pathway in breast cancers: from traditional signal transduction to direct nuclear translocalization. Breast Cancer Res Treat 95: 211-218, 2006.

9. Modjtahedi $\mathrm{H}$ and Essapen S: Epidermal growth factor receptor inhibitors in cancer treatment: advances, challenges and opportunities. Anticancer Drugs 20: 851-855, 2009.

10. Ciardiello $\mathrm{F}$ and Tortora G: EGFR antagonists in cancer treatment. N Engl J Med 358: 1160-1174, 2008.

11. Wong S: Cetuximab: an epidermal growth factor receptor monoclonal antibody for the treatment of colorectal cancer. Clin Ther 27: 684-694, 2005.

12. Ditsch N, Rückert S, Kümper C, et al: Trastuzumab (Herceptin ${ }^{\circledR}$ ): monoclonal antibody in the treatment of HER2/neu-overexpressing breast cancer in the metastatic and (neo)adjuvant situation. Breast Care 1: 78-84, 2006.

13. Cohen MH, Williams GA, Sridhara R, Chen G and Pazer R FDA drug approval summary: Gefitinib (ZD1839) (Iressa) tablet. Oncologist 8: 303-306, 2003.

14. Giusti RM, Shastri K, Pilaro AM, et al: U.S. Food and Drug Administration approval: panitumumab for epidermal growth factor receptor-expressing metastatic colorectal carcinoma with progression following fluoropyrimidine-, oxaliplatin-, and irinotecan-containing chemotherapy regimens. Clin Cancer Res 14: 1296-1302, 2008.

15. Cameron D, Casey M, Oliva C, Newstat B, Imwalle B and Geyer CE: Lapatinib plus capecitabine in women with HER-2positive advanced breast cancer: final survival analysis of a phase III randomized trial. Oncologist 15: 924-934, 2010.

16. Espinoza LA, Tone LG, Neto JB, Costa RS, Wang QJ and Ballejo G: Enhanced TGFalpha-EGFR expression and P53 gene alterations contributes to gastric tumors aggressiveness. Cancer Lett 212: 33-41,2004

17. Khambata-Ford S, Garrett CR, Meropol NJ, et al: Expression of epiregulin and amphiregulin and K-ras mutation status predict disease control in metastatic colorectal cancer patients treated with cetuximab. J Clin Oncol 25: 3230-3237, 2007.

18. Tol J, Dijkstra JR, Klomp M, et al: Markers for EGFR pathway activation as predictor of outcome in metastatic colorectal cancer patients treated with or without cetuximab. Eur J Cancer 46: 1997-2009, 2010.

19. Shia J, Klimstra DS, Li AR, et al: Epidermal growth factor receptor expression and gene amplification in colorectal carcinoma: an immunohistochemical and chromogenic in situ hybridization study. Mod Pathol 18: 1350-1356, 2005.

20. Cunningham MP, Thomas $\mathrm{H}$, Fan $\mathrm{Z}$ and Modjtahedi $\mathrm{H}$ : Responses of human colorectal tumor cells to treatment with the anti-epidermal growth factor receptor monoclonal antibody ICR62 used alone and in combination with the EGFR tyrosine kinase inhibitor gefitinib. Cancer Res 66: 7708-7715, 2006.

21. Solca F: Pharmacology and molecular mechanisms of BIBW2992 a potent irreversible dual EGFR/HER-2 kinase inhibitor of cancer therapy. Targ Oncol 2: S15, 2007.
22. Bordoni RE: Afatinib (BIBW-2992): a novel dual EGFR/ HER2neu inhibitor with promising activity in non-small-cell lung cancer. Therapy 8: 15-22, 2011.

23. Li D, Ambrogio L, Shimamura T, et al: BIBW2992, an irreversible EGFR/HER2 inhibitor highly effective in preclinical lung cancer models. Oncogene 27: 4702-4711, 2008.

24. Perera SA, Li D, Shimamura T, et al: HER2YVMA drives rapid development of adenosquamous lung tumors in mice that are sensitive to BIBW2992 and rapamycin combination therapy. Proc Natl Acad Sci USA 106: 474-479, 2009.

25. Nam H-J, Kim H-P, Yoon Y-K, et al: Antitumor activity of HM781-36B, an irreversible Pan-HER inhibitor, alone or in combination with cytotoxic chemotherapeutic agents in gastric cancer. Cancer Lett 302: 155-165, 2011.

26. Minkovsky N and Berezov A: BIBW-2992, a dual receptor tyrosine kinase inhibitor for the treatment of solid tumors. Curr Opin Investig Drugs 9: 1336-1346, 2008.

27. Eskens FA, Mom CH, Planting AS, et al: A phase I dose escalation study of BIBW 2992, an irreversible dual inhibitor of epidermal growth factor receptor 1 (EGFR) and 2 (HER2) tyrosine kinase in a 2-week on, 2-week off schedule in patients with advanced solid tumours. Br J Cancer 98: 80-85, 2008.

28. Yap TA, Vidal L, Adam J, et al: Phase I trial of the irreversible EGFR and HER2 kinase inhibitor BIBW 2992 in patients with advanced solid tumors. J Clin Oncol 28: 3965-3972, 2010.

29. Modjtahedi H, Styles JM and Dean CJ: The human EGF receptor as a target for cancer therapy: six new rat mAbs against the receptor on the breast carcinoma MDA-MB 468. Br J Cancer 67: 247-253, 1993

30. Cunningham MP, Thomas H, Marks C, Green M, Fan Z and Modjtahedi H: Co-targeting the EGFR and IGR-IR with antiEGFR monoclonal antibody ICR62 and the IGF-IR tyrosine kinase inhibitor NVP-AEW541 in colorectal cancer cells. Int J Oncol 33: 1107-1113, 2008.

31. Mendelsohn J and Baselga J: Status of epidermal growth factor receptor antagonists in the biology and treatment of cancer. J Clin Oncol 21: 2787-2799, 2003.

32. Italiano A, Saint-Paul MC, Caroli-Bosc FX, et al: Epidermal growth factor receptor (EGFR) status in primary colorectal tumors correlates with EGFR expression in related metastatic sites: biological and clinical implications. Ann Oncol 16: 1503-1507, 2005.

33. Han HS, Chang HJ, Hong YS, Kim SY, Lee KS and Jung KH: Epidermal growth factor receptor expression discrepancies in metastatic colorectal cancer patients treated with cetuximab plus irinotecan-based chemotherapy refractory to irinotecan and oxaliplatin. Dis Colon Rectum 52: 1144-1151, 2009.

34. Mao C, Liao RY and Chen Q: Loss of PTEN expression predicts resistance to EGFR-targeted monoclonal antibodies in patients with metastatic colorectal cancer. Br J Cancer 102: 940, 2010

35. Siddiqui A and Piperdi B: KRAS mutation in colon cancer: a marker of resistance to EGFR-I therapy. Ann Surg Oncol 17: 1168-1176, 2010.

36. Bouchahda M, Karaboué A, Saffroy R, et al: Acquired KRAS mutations during progression of colorectal cancer metastases: possible implications for therapy and prognosis. Cancer Chemother Pharmacol 66: 605-609, 2010.

37. Amado RG, Wolf M, Peeters M, et al: Wild-type KRAS is required for panitumumab efficacy in patients with metastatic colorectal cancer. J Clin Oncol 26: 1626-1634, 2008.

38. Lievre A, Bachet J-B, Le Corre D, et al: KRAS mutation status is predictive of response to cetuximab therapy in colorectal cancer. Cancer Res 66: 3992-3995, 2006.

39. Allegra CJ, Jessup JM, Somerfield MR, et al: American Society of Clinical Oncology provisional clinical opinion: testing for KRAS gene mutations in patients with metastatic colorectal carcinoma to predict response to aAnti-epidermal growth factor receptor monoclonal antibody therapy. J Clin Oncol 27: 2091-2096, 2009.

40. Wang Z, Li Y, Liu ET and Yu Q: Susceptibility to cell death induced by blockade of MAPK pathway in human colorectal cancer cells carrying Ras mutations is dependent on p53 status. Biochem Biophys Res Commun 322: 609-613, 2004.

41. Balmanno K, Chell SD, Gillings AS, Hayat S and Cook SJ: Intrinsic resistance to the MEK1/2 inhibitor AZD6244 (ARRY142886) is associated with weak ERK1/2 signalling and/or strong PI3K signalling in colorectal cancer cell lines. Int J Cancer 125: 2332-2341, 2009

42. Benvenuti S, Sartore-Bianchi A, Di Nicolantonio F, et al: Oncogenic activation of the RAS/RAF signaling pathway impairs the response of metastatic colorectal cancers to anti-epidermal growth factor receptor antibody therapies. Cancer Res 67: 2643-2648, 2007. 
43. Matar P, Rojo F, Cassia R, et al: Combined epidermal growth factor receptor targeting with the tyrosine kinase inhibitor gefitinib (ZD1839) and the monoclonal antibody cetuximab (IMC-C225). Clin Cancer Res 10: 6487-6501, 2004.

44. Lee JC, Wang ST, Chow NH and Yang HB: Investigation of the prognostic value of coexpressed erbB family members for the survival of colorectal cancer patients after curative surgery. Eur J Cancer 38: 1065-1071, 2002.
45. Baiocchi G, Lopes A, Coudry R, et al: ErbB family immunohistochemical expression in colorectal cancer patients with higher risk of recurrence after radical surgery. Int J Colorectal Dis 24: 1059-1068, 2009

46. Schütze C, Dörfler A, Eicheler W, et al: Combination of EGFR/ HER 2 tyrosine kinase inhibition by BIBW 2992 and BIBW 2669 with irradiation in FaDu human squamous cell carcinoma. Strahlenther Onkol 183: 256-264, 2007. 